\title{
DETERMINANTES DO DESMATAMENTO EM PEQUENAS PROPRIEDADES NA AMAZÔNIA: UM ESTUDO DE CASO EM URUARÁ -PA ${ }^{1}$
}

\author{
Ritaumaria de J. Pereira ${ }^{2}$ \\ Wilson da Cruz Vieira ${ }^{3}$ \\ João Eustáquio de Lima \\ Marcellus Marques Caldas ${ }^{5}$
}

Resumo - Este trabalho analisou os determinantes do desmatamento em pequenas propriedades na Amazônia, em uma área de colonização localizada ao longo da rodovia Transamazônica, no município de Uruará - PA. Foram aplicados 138 questionários na área de estudo, durante os meses de julho e agosto de 2002. Estimou-se um modelo Tobit com seletividade amostral, utilizando o método de Heckman, em dois estágios, visando corrigir possíveis problemas de viés e inconsistência existentes nas estimativas por MQO. Os resultados encontrados sugerem que os principais determinantes do desmatamento possam ser a distância da estrada principal e o número de diárias pagas no período de um ano, os quais foram significativos a $1 \%$ e $5 \%$, respectivamente. A presença da pecuária foi também importante para determinar as chances de ocorrer desmatamento na região estudada.

Palavras-chave: Amazônia, desmatamento, colonização, modelo Tobit

\footnotetext{
1 Recebido em 10/05/2004. Aceito em 16/08/2004.

Este trabalho baseia-se na dissertação de mestrado da primeira autora.

2 Engenheira-Agrônoma, M.S. em Economia Aplicada, Departamento de Economia Rural,Universidade Federal de Viçosa. E-mail: rithau@yahoo.com.br.

3 Professor Adjunto do Departamento de Economia Rural, Universidade Federal de Viçosa. CEP 36570-000. Viçosa - MG. E-mail: wvieira@ufv.br.

4 Professor Titular do Departamento de Economia Rural, Universidade Federal de Viçosa. CEP 36570-000. Viçosa-MG.E-mail: jelima@ufv.br.

5 Pesquisador vinculado à Michigan State University. E-mail: caldasma@msu.edu.

${ }^{6}$ Para mais detalhes, ver, por exemplo, Andrade (2003).
} 


\section{Introdução}

Não obstante sua importância no suporte à biodiversidade e no ciclo da água, a Amazônia brasileira apresenta a taxa absoluta mundial mais alta de destruição de floresta, calculada atualmente em uma média de quase dois milhões de hectares por ano (Laurance et al., 2001).

Esse processo de destruição da floresta nativa acelerou-se a partir da segunda metade da década de 1960, quando o governo militar brasileiro, com o objetivo de desenvolver e integrar a região ao resto do país, estabeleceu uma série de atos e decretos legislativos, aliados a um ambicioso projeto de construção de estradas, planos para colonização e incentivos fiscais que visavam favorecer a criação de novas atividades agrícolas e industriais nessa região (Mahar, 1989).

Após esse período e com o processo de povoamento em andamento, verificou-se que vastas áreas de floresta foram desmatadas para dar lugar a pastos ou culturas agrícolas. De acordo com Cattaneo (2002), a expansão geográfica da fronteira agrícola brasileira tem tido papel importante no processo de desmatamento na Amazônia, e o uso das terras para agricultura e pecuária tem sido uma das principais causas desse desmatamento, visto que os assentamentos locais estimulados por essas atividades têm assumido papel crucial nesse processo.

Após a decisão do governo brasileiro de incentivar o povoamento da Amazônia, houve incremento na população local de cerca de $80 \%$, fato que desencadeou a transformação de milhões de hectares de floresta densa em terras agricultáveis, no período de 1970 a 1985 (Andersen e Reis, 1997).

Previa-se, inicialmente, que ocorresse forte imigração inter-regional a partir de assentamentos permanentes e auto-suficientes na fronteira agrícola (Mahar, 1978). Entretanto, o que houve foi a implantação de sistemas de produção caracterizados pelo uso intensivo do trabalho familiar e por tecnologia agrícola simples, seguidos por forte tendência à criação 
de gado e à incorporação contínua de novas áreas à agricultura, com pequeno reconhecimento pela preservação dos recursos naturais.

A incorporação contínua de novas áreas de floresta para produção agrícola resultou do baixo nível tecnológico dos produtores atraídos à região e dos baixos índices de fertilidade dos solos amazônicos. O produtor atraído à região levou consigo práticas agrícolas de sua região de origem, na maioria das vezes não adaptáveis às condições locais. Esse processo resultou na chamada agricultura migratória, em que, após quatro ou cinco ciclos de produção, a área é abandonada e novas áreas de floresta são incorporadas para produção agrícola (Homma et al., 1998).

Não obstante os estudos já existentes, esse processo de desmatamento e incorporação de áreas para atividades agropecuárias ainda é pouco conhecido. Há necessidade de investigar melhor as características do desmatamento e de seus atores em locais, identificando as razões que levam os proprietários a desmatarem áreas cada vez maiores que as estabelecidas pela legislação e introduzirem novas atividades sem se preocuparem com a sustentabilidade da exploração.

Dessa forma, com vistas em analisar os principais determinantes do desmatamento em pequenas propriedades na Amazônia, selecionou-se o município de Uruará-PA para um estudo de caso, pelo fato de essa região constituir uma área de fronteira agrícola com baixa densidade populacional e mercados emergentes, a qual se formou a partir da construção da rodovia Transamazônica, envolvendo assentamentos e desencadeando, desde então, considerável histórico de desmatamento.

O objetivo geral deste trabalho foi analisar a área destinada à agropecuária, o uso de técnicas agrícolas e seus efeitos sobre o desmatamento em uma área de colonização em Uruará - PA. Especificamente, buscou-se:

a) Identificar e caracterizar os principais fatores influenciadores do desmatamento por parte dos pequenos produtores;

b) Relacionar as variáveis explicativas do desmatamento em Uruará PA; e 
c) Avaliar os efeitos dos principais fatores que afetam o desmatamento na região.

\section{Referencial teórico}

Um modelo econômico aplicado à situação amazônica, apresentado por Homma et al. (1998), de derrubada e queimada pelos pequenos produtores assentados ao longo da rodovia Transamazônica, foi utilizado como referencial teórico neste trabalho. Por este modelo, analisaram-se sistemas agrícolas diversificados na região, com pecuária e culturas anuais e perenes.

De acordo com Homma et al. (1998), a derrubada e a queimada de floresta densa ou de capoeira (vegetação secundária proveniente de desmatamentos de floresta densa, anos anteriores) dependem de uma série de variáveis econômicas e tecnológicas, dentre as quais se destacam a idade da capoeira, a disponibilidade e preço da terra e da mão-deobra, o custo da derrubada e o preço do produto.

Na Figura 1 apresenta-se uma situação de área de fronteira agrícola, em que o recurso terra é considerado abundante e o custo da utilização da terra está relacionado com a mão-de-obra necessária para seu cultivo. O custo de uso da terra é considerado fixo, ou seja, é dado por $w L_{i}$, em que $w$ representa o salário e $L$, mão-de-obra por unidade de área $[i$ representa o tipo de cobertura vegetal (c), com $i=0$ (floresta densa ou capoeirão) e $i=1$ (capoeira nova ou juquira)]. 


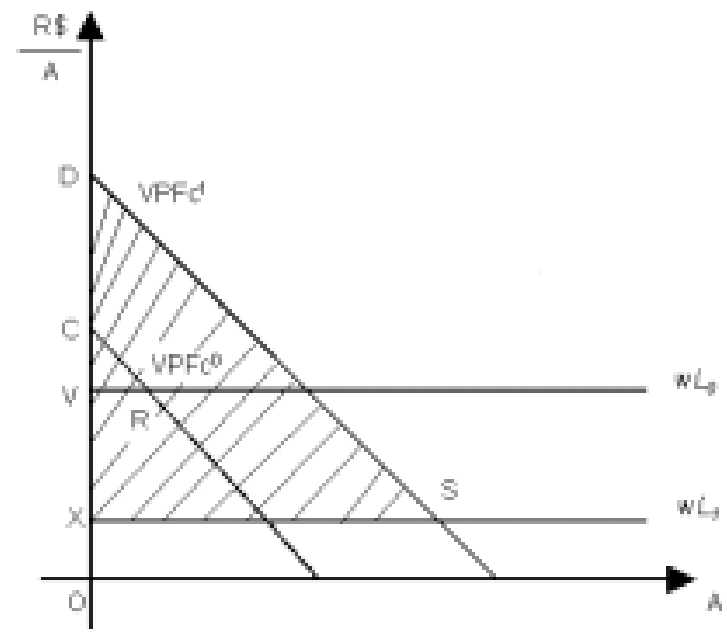

Fonte: Adaptado de Homma et al. (1998).

Figura 1 - Relação entre produtividade física marginal, preço do produto e custo na utilização da terra na Amazônia, em diferentes estádios de cobertura vegetal.

Nesse modelo, para diferentes tipos de cobertura vegetal, os valores do produto físico marginal (VPF), a determinado preço do produto, devem igualar-se ao custo à margem, sendo a área utilizada (A) representada pelo eixo horizontal. Dessa forma, as disponibilidades de terra e de mãode-obra e os preços dos produtos condicionam a utilização dos diferentes tipos de cobertura vegetal.

Por um lado, uma queda nos níveis de preços do produto, por exemplo, desloca a curva do valor do produto físico marginal para baixo, desestimulando o uso de solos que apresentam baixa produtividade, ou seja, aqueles com cobertura vegetal recente (juquira). Por outro, nas áreas de ocupação recente, os baixos preços dos produtos, decorrentes da distância ao mercado principal, por exemplo, são compensados pela maior produtividade agrícola. Preços dos produtos favoráveis aos produtores, portanto, tendem a reduzir as pressões por desmatamentos e queimadas de áreas de floresta densa, em detrimento de áreas com vegetação secundária (capoeiras). 
No caso de haver limitações de mão-de-obra e o fator terra não for restritivo, tanto a derrubada de novas áreas de floresta densa quanto a utilização de copoeiras com longo tempo de pousio tornam-se mais atraentes aos pequenos produtores. Nesse caso, a maior produtividade das lavouras compensaria o custo mais elevado da mão-de-obra. Na Figura 1 podem-se visualizar as escolhas dos pequenos produtores, considerando as áreas com diferentes tipos de cobertura vegetal.

Os lucros são representados pelas áreas hachuradas entre as curvas de produtos físicos marginais e as linhas de horizonte de custos (Figura 1). Com esta estrutura de produção e custos, o produtor teria maiores vantagens com a utilização de floresta densa ou vegetação secundária mais antiga, quando comparado com capoeira nova ou juquira. Os ganhos do produtor com capoeirão ou floresta densa seriam dados pela área XSD e, com capoeira nova, pela área VRC.

Outra situação importante e distinta da apresentada na Figura 1, que pode ser considerada, é a que surge quando há valorização da terra e que ocorre com o crescimento populacional e a proximidade de áreas urbanas. Nesse caso, a terra passa a ser fator limitante e tende a haver expansão capitalista no campo, provocando a agregação das propriedades e a entrada de atividades como pecuária e culturas perenes. Com isso, há redução da área disponível às atividades dos pequenos produtores, que passam a utilizar mais intensivamente a terra ou migram para novas áreas.

Além das decisões de produção, os pequenos produtores têm que comercializar seus produtos. As condições de mercado nas áreas de colonização na Amazônia estão diretamente ligadas à proximidade do pequeno produtor às estradas principais e também às suas condições de tráfego. De acordo com Mahar (1989), quanto mais longe das estradas, mais altos são os custos com insumos e transportes, o que dificulta o acesso do pequeno produtor às tecnologias modernas. 


\section{Metodologia}

Dadas as características do processo de desmatamento na Amazônia e das informações levantadas na área de estudo, utilizou-se, neste trabalho, o modelo Tobit com seletividade amostral, estimado pelo método proposto por Heckman (1974).

Neste trabalho, as estimativas da área total desmatada baseiam-se em uma amostra censurada, a qual está sujeita a um viés de seletividade, fato que torna as estimativas por Mínimos Quadrados Ordinários (MQO) viesadas e inconsistentes, uma vez que tende a considerar resultados somente das propriedades onde houve desmatamento. Com a finalidade de corrigir esse problema, adotou-se, dessa forma, o procedimento em dois estágios.

No primeiro estágio, o modelo proposto compreende uma modelagem de decisão. Neste estudo, observou-se a probabilidade de desmatar, ou não, pela regressão de um modelo Logit, no qual a variável dependente terá valores de 0 (se não houver desmatamento) a 1 (se houver desmatamento), em que a probabilidade de desmatar é dada pela seguinte equação:

$$
P_{i}=f\left(X_{i}^{\prime} \beta\right)=\frac{1}{1+e^{-Z_{i}}},
$$

em que $P_{i}$ é a probabilidade de o agricultor desmatar, $Z_{i}=X_{i}^{\prime} \beta ; f$, função de distribuição de probabilidade (acumulada) logística; $X_{i}$, vetor de variáveis explicativas; e $\beta$, vetor de parâmetros a serem estimados.

A variável $P_{i}$ não é observada; tem-se $y_{i}=1$ se houver desmatamento e $y_{i}=0$, se não houver. Como variável explicativa considerou-se apenas a existência de pecuária, medida em número de cabeças de gado. 
Esta escolha se deu pelo fato de a atividade pecuária estar se expandindo atualmente, requerendo-se, dessa forma, novas áreas para formação de pastos.

Após a estimação do modelo Logit, pelo qual se avalia a probabilidade de desmatar ou não, o segundo estágio compreende a estimação de uma função para a área total desmatada, como variável dependente, eliminando-se o viés de seletividade amostral por meio da introdução de uma variável lambda $(\lambda)$, conhecida como inverso da razão de Mills, como uma variável explicativa adicional, conforme sugerido por Heckman (1974). A variável lambda ( $\lambda$ ) é dada pela seguinte expressão:

$\lambda_{i}=\frac{\phi\left(\sigma Z_{i} / \sigma_{u}\right)}{\Phi\left(\sigma Z_{i} / \sigma_{u}\right)}, i=1,2,3, \mathrm{~K}, n$,

em que $\phi$ e $\Phi$ representam, respectivamente, as funções de densidade de probabilidade e de distribuição cumulativa normal padrão (Greene, 1997). $\sigma_{u}$ é o desvio-padrão do erro aleatório da regressão da variável dependente não-diretamente observada ( $1^{\circ}$ estágio) e $\sigma$ é o desvio-padrão relativo à amostra censurada ( $2^{\circ}$ estágio). ${ }^{6}$

A variável lambda ( $\lambda$ ) passa a fazer parte da equação utilizada no segundo estágio, como variável explicativa e significativa, mostrando, assim, a importância de se considerarem os dois estágios no processo de estimação.

Neste segundo estágio, estimou-se a seguinte equação:

${ }^{6}$ Para mais detalhes, ver, por exemplo, Andrade (2003). 
$A t d_{i}=\beta_{o}+\beta_{1} E s c_{i}+\beta_{2} N t p f_{i}+\beta_{3} D e p_{i}+\beta_{4} D P 2001+\beta_{5} G a d o+\beta_{6} A s t e q+\beta_{7} A g s u b+$ $\beta_{8} A d q+\beta_{9}$ Pest $+\alpha \lambda_{i}+\varepsilon_{i}$

em que

Atd é a área total desmatada, em hectares;

Esc, nível de escolaridade, representado em anos em que o proprietário freqüentou a escola;

Ntpf, número total de pessoas que trabalham fora e que moram no lote;

Dep, distância da propriedade em relação à estrada principal (Transamazônica), em Km;

DP2001, número de diárias pagas por trabalho realizado dentro do lote, no período de um ano;

Gado, número total de cabeças de gado na propriedade, sendo do proprietário e, ou, de terceiros que alugam o pasto;

Astec igual a 1, se o produtor receber visita de algum órgão de assistência técnica; caso contrário, igual a 0 ;

Agsub igual a 1, se o produtor utilizou aração, gradagem e, ou, subsolagem; caso contrário, igual a 0 ;

$A d q$ igual a 1, se o produtor utilizar adubo químico em sua propriedade; caso contrário, igual a 0 ;

Pest igual a 1, se o produtor fizer uso de fungicida, inseticida e, ou, 
herbicida; caso contrário, igual a 0 ;

$\lambda$, inverso da razão de Mills; e

$\varepsilon$, erro aleatório.

A definição e o sinal esperado para o coeficiente de cada variável estão contidos na Tabela 1.

Tabela 1 - Variáveis componentes do modelo empírico e sinais esperados

\begin{tabular}{|c|c|c|}
\hline Variável & Sinal esperado & Descrição \\
\hline Atd* & dependente & Área total desmatada, em ha \\
\hline Esc & + & Nível de escolaridade, em anos de freqüência à escola \\
\hline Ntpf & + & Número total de pessoas que trabalham fora e moram no lote \\
\hline Dep & - & Distância da estrada principal, rodovia Transamazônica, em km \\
\hline DP2001 & + & Número de diárias pagas no período de um ano \\
\hline Gado & + & Número de cabeças de gado na propriedade \\
\hline \multirow[t]{2}{*}{$\lambda$} & $?$ & Inverso da razão de Mills \\
\hline & & Dummies \\
\hline Astec & + & $\begin{array}{l}\text { Igual a } 1 \text {, se recebeu visita de algum órgão de assistência } \\
\text { técnica, caso contrário, igual a } 0\end{array}$ \\
\hline Agsub & - & $\begin{array}{l}\text { Igual a } 1 \text {, se o produtor utilizar aração, gradagem e, ou, } \\
\text { subsolagem, caso contrário, igual a } 0\end{array}$ \\
\hline Adq & - & $\begin{array}{l}\text { Igual a } 1 \text {, se o produtor utilizar adubo químico, caso contrário, } \\
\text { igual a } 0\end{array}$ \\
\hline Pest & + & $\begin{array}{l}\text { Igual a } 1 \text {, se o produtor fizer uso de fungicida, inseticida e, ou, } \\
\text { herbicida, caso contrário, igual a } 0\end{array}$ \\
\hline
\end{tabular}

* O valor da área total desmatada (Atd) foi calculado pela soma das áreas totais com culturas perenes, anuais, pasto e capoeira, conforme informado pelos produtores, em seus respectivos lotes de 100 hectares.

Os dados utilizados foram obtidos por meio de entrevista direta com os proprietários rurais utilizando questionário previamente testado. Foram aplicados 138 questionários a produtores em Uruará, PA, os quais agregaram 224 lotes nas estradas principal e vicinais, entre julho e agosto de 2002. Foram selecionados 137 lotes, cuja formação era de 100 ha, representando, dessa forma, o tamanho original do lote durante a formação 
das áreas de colonização. Os demais foram excluídos do modelo proposto, pelo fato de alguns colonos terem acumulado partes de outros lotes ou então, terem desfeito de parte de seu lote, por motivos diversos.

\section{Resultados e discussão}

\subsection{Caraterísticas da área estudada}

Em Uruará, PA, a utilização das áreas de colonização está voltada para culturas anuais, culturas perenes e pastagem. Muitas áreas apresentam formação de florestas secundárias (capoeiras) com idades diversas e são utilizadas somente após determinado tempo de pousio. Quanto maior esse período, maior a produtividade, sendo melhor, então, desmatar áreas com formações mais antigas, uma vez que se entende que, nestas, o lucro será maior.

Em relação ao nível de educação dos colonos estabelecidos na região, na área em estudo, $67 \%$ dos entrevistados nunca freqüentaram a escola. Um nível mais elevado de escolaridade permite ao pequeno produtor rural maior eficiência na produção, podendo ele, dessa forma, ter maior acesso aos novos insumos, às técnicas agrícolas e ao mercado consumidor e, consequentemente, incrementar os níveis de desmatamento.

O número de pessoas que trabalham no lote define a quantidade de mãode-obra disponível e determinará o quanto irão trocar entre trabalho e lazer. Quanto mais voltadas para a atividade de subsistência, menor será o incremento de cada unidade de trabalho, de acordo com o grau de satisfação da família. Se houver produção para obtenção de lucro, maior será o incremento do desmatamento, dadas as características do produtor em relação ao mercado consumidor e à disponibilidade de mão-deobra. 
No estabelecimento de culturas perenes, maior quantidade de mão-deobra empregada se faz necessária na época do preparo do solo e da colheita. Para plantio de culturas anuais, comumente é empregada mãode-obra familiar. A formação de pastos requer apenas contratação de mão-de-obra no período do estabelecimento da área.

O trabalho fora da propriedade constitui fonte de renda, que, além de servir para a satisfação das necessidades básicas, serve para investimentos na produção mecanizada ou, ainda, para acúmulo de riqueza, para que sejam feitos investimentos futuros, substituindo, dessa forma, o capital por trabalho (Baraclough e Ghimire, 1990).

As condições de acesso ao mercado dependem diretamente da distância média dos produtores à estrada principal. As estradas secundárias, onde está distribuída a maioria dos lotes nas áreas de colonização, apresentam condições de tráfego precárias, o que impossibilita os pequenos produtores a escoarem a produção para o mercado mais próximo. Os colonos que se estabelecem próximos às rodovias principais conseguem se ajustar melhor ao mercado, uma vez que possuem maior acesso a ele e, por estarem mais próximos aos mercados, contribuem, de forma consistente, para o aumento dos índices de desmatamento.

Apesar da intensificação da agricultura moderna nos últimos anos, o cenário encontrado na área em estudo mostra que o produtor estabelecido na região não tende a acompanhar as modificações tecnológicas e que é muito incipiente, ainda, o acesso a pesticidas, fertilizantes e máquinas agrícolas. Esse resultado relaciona-se diretamente com as dificuldades que o produtor encontra em custear os gastos com transporte, fato que também onera o custo dos insumos e também dos produtos agrícolas. Percebeu-se, dessa forma, que as dificuldades de acesso não permitiram o uso intensivo de insumos, uma vez que se observou que em apenas $20,44 \%$ das propriedades foi feito uso de adubo químico e em apenas $10,22 \%$ das propriedades visitadas houve uso de máquinas agrícolas. O uso de pesticidas foi observado em $42,33 \%$ das propriedades avaliadas. 


\subsection{Correlação entre as variáveis analisadas}

Pela análise de correlação, buscou-se verificar o grau de relacionamento entre a área total desmatada e as demais variáveis destacadas como influenciadoras do desmatamento em Uruará-PA, 2002 (Tabela 2).

Tabela 2 - Coeficiente de correlação da Área Total Desmatada e das variáveis explicativas do desmatamento em Uruará-PA, 2002

Nível de escolaridade, em anos de freqüência à escola (Esc)

$0,3375 * * *$

Número de pessoas que moram no lote e trabalham fora (Ntpf) $0,1598 *$

Distância da estrada principal, em km (Dep) $-0,3375 * * *$

Número de diárias pagas durante 2001 (DP2001)

$0,3565 * * *$

Número de cabeças de gado na propriedade (Gado) $0,3171 * * *$

Recebimento(1) ou não(0) de assistência técnica (Astec) $-0,1109^{\mathrm{NS}}$

Uso (1) ou não (0) de aração, gradagem e subsolagem (Agsub) $0,1376^{\mathrm{NS}}$

Uso (1) ou não (0) de adubo químico (Adq) $0,2741^{*}$

Uso (1) ou não (0) de pesticidas (Pest) $0,3136 * * *$

*** Significativo a $1 \%$ de probabilidade; * significativo a $10 \%$ de probabilidade; NS, não significativo.

Fonte: Dados da pesquisa.

De modo geral, as correlações entre área desmatada e as variáveis selecionadas mostraram-se relativamente fracas, porém, estatisticamente significativas. Não houve correlação significativa somente com assistência técnica e uso de aração, gradagem e subsolagem. A correlação entre área desmatada e número de pessoas que moram no lote e trabalham fora foi positiva, mas significativa somente a $10 \%$ de probabilidade. As outras correlações foram significativas a $1 \%$ de probabilidade.

Observou-se correlação positiva entre área desmatada e escolaridade, número de diárias pagas em 2001, número de cabeças de gado na propriedade, uso de adubo químico e uso de pesticidas. O incremento dessas variáveis, individualmente, tende a aumentar a área desmatada. 
A área desmatada se relaciona negativamente com a distância da estrada principal indicando que propriedades mais distantes tendem a desmatar menos. Pode-se inferir, também, que o desmatamento será mais intenso ao longo das estradas principais uma vez que estas possibilitaram maior escoamento da produção.

\subsection{Determinantes do desmatamento}

A Tabela 3 apresenta os resultados das estimativas da equação que explica a probabilidade de desmatamento (primeiro estágio) e da equação para área desmatada (segundo estágio) para a região de Uruará - PA, 2002. 
Tabela 3 - Coeficientes estimados do modelo Tobit, Uruará, PA, 2002

\begin{tabular}{|c|c|c|}
\hline \multicolumn{3}{|c|}{ Primeiro estágio } \\
\hline Variável & Coeficiente (erro-padrão) & P-valor \\
\hline Constante & $\begin{array}{c}1,0336 \\
(0,1440)\end{array}$ & $0,0000^{* * * * *}$ \\
\hline Gado & $\begin{array}{c}0,0013 \\
(0,0013)\end{array}$ & $0,0642 * *$ \\
\hline
\end{tabular}

Obs. com DESMAT $=0 \quad 25$

Obs. Com DESMAT $=1112$

Total

137

\begin{tabular}{|c|c|c|}
\hline \multicolumn{3}{|c|}{$\begin{array}{c}\text { Segundo estágio } \\
\text { Variável dependente }=\text { Área total desmatada }\end{array}$} \\
\hline Constante & $\begin{array}{c}190,6332 \\
(93,87868)\end{array}$ & $0,0449 * * *$ \\
\hline $\begin{array}{l}\text { Nível de escolaridade, em anos de } \\
\text { freqüência à escola (Esc) }\end{array}$ & $\begin{array}{c}0,481751 \\
(0,786963)\end{array}$ & $0,5418^{\mathrm{NS}}$ \\
\hline $\begin{array}{l}\text { Número de cabeças de gado na propriedade } \\
\text { (Gado) }\end{array}$ & $\begin{array}{c}0,633506 \\
(0,363421)\end{array}$ & $0,0843 * *$ \\
\hline $\begin{array}{l}\text { Distância da estrada principal, em km } \\
\text { (Dep) }\end{array}$ & $\begin{array}{l}-0,359619 \\
(0,154839)\end{array}$ & $0,0222 * * *$ \\
\hline $\begin{array}{l}\text { Número de diárias pagas no período de um } \\
\text { ano (DP2001) }\end{array}$ & $\begin{array}{c}0,042801 \\
(0,014536)\end{array}$ & $0,0040 * * * *$ \\
\hline $\begin{array}{l}\text { Recebimento (1) ou não (0) de assistência } \\
\text { técnica (Astec) }\end{array}$ & $\begin{array}{c}1,397979 \\
(5,280255)\end{array}$ & $0,7917^{\mathrm{NS}}$ \\
\hline Uso (1) ou não (0) de adubo químico (Adq) & $\begin{array}{l}-1,385245 \\
(5,547899)\end{array}$ & $0,8033^{\mathrm{NS}}$ \\
\hline Uso (1) ou não (0) de pesticida (Pest) & $\begin{array}{c}7,067017 \\
(4,459400)\end{array}$ & $0,1162 *$ \\
\hline $\begin{array}{l}\text { Uso (1) ou não (0) de aração, gradagem e } \\
\text { subsolagem (Agsub) }\end{array}$ & $\begin{array}{l}-1,494609 \\
(8,588767)\end{array}$ & $0,8622^{\mathrm{NS}}$ \\
\hline $\begin{array}{l}\text { Número total de pessoas que moram no } \\
\text { lote e trabalham fora (Ntpf) }\end{array}$ & $\begin{array}{c}2,672830 \\
(1,426028)\end{array}$ & $0,0638 * *$ \\
\hline Inverso da razão de Mills $(\lambda)$ & $\begin{array}{l}-559,2350 \\
(345,4696)\end{array}$ & $0,1086^{*}$ \\
\hline & & $\begin{aligned} \mathrm{R}^{2} & =0,2952 \\
\mathrm{~F} & =4,2308 \\
\text { Prob } \mathrm{F} & =0,0000\end{aligned}$ \\
\hline
\end{tabular}

Nota: $* * * *, * * *, * * \mathrm{e} *$, significativos a $1,5,10$ e $15 \%$, respectivamente. NS nãosignificativo.

Fonte: Dados da pesquisa. 
Os resultados apresentados na Tabela 3 indicam que todos os coeficientes obtiveram os sinais esperados, exceto os relacionados com o recebimento ou não de assistência técnica (Astec), uso de máquinas agrícolas (Agsub) e adubo químico (Adq), no segundo estágio do modelo.

No primeiro estágio, a variável representativa do número de cabeças de gado na propriedade (Gado) explicou a probabilidade de desmatar e foi significativa a $10 \%$ de probabilidade. $\mathrm{O}$ incremento da pecuária na região tende a aumentar as chances de desmatamento.

A estimação, para o segundo estágio do modelo, mostrou coeficiente de determinação $\left(\mathrm{R}^{2}\right)$ abaixo de $30 \%$. No entanto, a combinação dos resultados do teste $\mathrm{F}$ e $\mathrm{R}^{2}$ indica que os resultados foram significativos a $1 \%$ de probabilidade, o que revela que houve bom ajustamento do modelo aos dados.

Trabalhos desenvolvidos por Wood et al. (2001) e Perz (2003), também no município de Uruará, PA, revelaram valores do $\mathrm{R}^{2}$ próximos ao encontrado trabalho. Esses valores inexpressivos podem ser explicados por tratar-se de um modelo que usa dados de seção cruzada, os quais, de acordo com Gujarati (2000), tendem a apresentar essa característica.

No modelo proposto, a variável relacionada com o número de diárias pagas no período de um ano (DP2001) mostrou-se mais representativa da área total desmatada, apresentando-se significativa a $1 \%$.

A variável relacionada à distância da estrada principal (Dep) foi significativa a 5\%, enquanto as relacionadas com número total de pessoas que moravam no lote e trabalhavam fora (Ntpf) e com número de cabeças de gado na propriedade (Gado) foram significativas a $10 \%$.

O parâmetro relacionado com uso ou não de pesticidas (Pest), apresentou significância somente de $15 \%$, diferentemente das outras variáveis representativas do uso de tecnologias, como uso de máquinas agrícolas (Agsub) e adubo químico (Adq), as quais foram não-significativas. Esse fato pode estar relacionado com o maior uso de pesticidas em relação às 
outras variáveis proxies de tecnologia. A variável Dummy, representativa do recebimento ou não de assistência técnica (Astec), também foi não-significativa, o que também pode ser explicado pelo seu baixo índice na região.

Diferentemente da análise de correlação simples, a variável representativa do nível de escolaridade, quando analisada em conjunto com outras variáveis, se mostrou não-significativa, quando apresentados os resultados do segundo estágio do modelo; entretanto, o sinal positivo, representado pelo seu coeficiente, confirma que os níveis de desmatamento aumentam de acordo com o maior nível educacional.

A dificuldade citada na utilização das chamadas proxies de tecnologia é o seu alto custo, gerado pela dificuldade de acesso às áreas de colonização e também pela falta de conhecimento, uma vez que, como mostrado anteriormente, em poucas propriedades analisadas houve visita de algum órgão de assistência técnica.

Então, para que se aumentem os investimentos na utilização de máquinas e fertilizantes, deve haver garantia de que esses investimentos tenham retorno, uma vez que as dificuldades enfrentada no transporte da produção gerada na propriedade são ainda muito grandes e envolvem custos muito altos, devido ao pequeno período anual em que a Transamazônica, principal rodovia de acesso à região, é transitável.

\section{Conclusões}

Pelo modelo utilizado neste trabalho, constatou-se que as variáveis mais representativas das áreas totais desmatadas foram a distância da estrada principal e o número de diárias pagas no período de um ano. Dessa forma, observou-se que é importante compreender que existem dois tipos de colonos estabelecidos na área - os que se estabeleceram distante do mercado, razão da dificuldade de vender seus produtos e de acesso às tecnologias modernas, os quais continuam praticando a agricultura 
itinerante de subsistência; e aqueles que se estabeleceram próximos ao mercado consumidor e desenvolveram atividades mais voltadas ao mercado, como criação de gado.

Entende-se, então, que se houver uma política de incentivo que proporcione aumentos dos níveis educacionais por meio de conscientização e de assistência técnica adequada, a utilização das áreas agrícolas pode ser feita de forma mais consciente, evitando, dessa forma, a agricultura migratória, reduzindo a utilização de novas áreas de floresta e aproveitando, de forma otimizada, as áreas que já se encontram desmatadas atualmente. Porém, é importante considerar, nesse contexto, o uso do solo nas áreas de floresta tropical, de modo a não continuar nos ritmos atuais de desmatamento.

Nesse contexto, percebe-se que a implantação de novas políticas regionais é necessária, entretanto, deve ser seguida de um planejamento que observe os locais e a capacidade produtiva da região.

Devido aos diversos fatores que servem como indicativos de desmatamento, é difícil estabelecer somente as variáveis estudadas neste trabalho como causadoras do desmatamento na região. Sugere-se que sejam feitos estudos futuros na região, observando a interação entre os madeireiros e os colonos em Uruará, PA, e também a influência dos grandes pecuaristas no desmatamento, uma vez que estes estão adquirindo lotes a expandindo suas áreas de forma aleatória e sem nenhuma fiscalização que estabeleça os limites do desmatamento.

Outro aspecto observado é que o estado deveria exercer papel importante na fiscalização do desmatamento na Amazônia, oferecendo, por meio de órgãos competentes, assistência técnica e gerando tecnologias produtivas e sustentáveis para a região, como formas alternativas de exploração da área, com a finalidade de diminuir os atuais níveis de desmatamento. 


\section{Referências Bibliográficas}

ANDERSEN, L.E. e REIS, E. J. Deforestation, development, and government policy in the Brazilian Amazon: an econometric analysis. Brasília: IPEA. 1997. 24p. (Texto para discussão 513).

ANDRADE, V. D. A. O papel do estabelecimento agrícola e das características pessoais e familiares na alocação de trabalho no meio rural brasileiro. Viçosa: UFV, 2003. 136p. (Tese de Doutorado).

BARACLOUGH, S. e GHIMIRE, K. The social dynamics of deforestation in developing countries: Principal issues and research priorities. Washington: United Nations Research Institute for Social Development. 1990. 46p. (Texto para discussão).

CATTANEO, A. A general equilibrium analysis of technology, migration and deforestation in the Brazilian Amazon. In: ANGELSEN, A. e KAIMOWITZ, D. (eds). Agricultural Technologies and Tropical Deforestation. New York: CABI/CIFOR. p. 69-90. 2002.

GREENE, W. H. Econometric analysis. New Jersey: Prentice Hall. 3. Ed. 1997. 1075p

GUJARATI, D. N. Econometria básica. São Paulo: Makron Books. 3.Ed.. 2000. 846p

HECKMAN, J. Shadow prices, market wages and labour supply. Econometrica, V.42, No.4, p.679-694, 1974.

HOMMA, A. K. O.; WALKER, R. T.; SCATENA, F. N. CONTO, A. J. de; CARVALHO, R. de A.; FERREIRA, A. P.; SANTOS, A. I. M. dos. Redução dos desmatamentos na Amazônia: política agrícola ou ambiental? In: HOMMA, A. K. O. (editor). Amazônia: Meio Ambiente e Desenvolvimento Agrícola. Brasília: EMBRAPA. 1998. p. 119141. 
LAURANCE, W. F.; COCHRANE M. A.; BERGEN S.; FEARNSIDE, P. M.; DELAMÔNICA P.; CHRISTOPHER, B. de.; D'ANGELO, S.; FERNANDES T. The Future of the Brazilian Amazon. Science. n. 291. 2001. 4p.

MAHAR, D. J. Desenvolvimento econômico da Amazônia: Uma análise das políticas governamentais. Rio de Janeiro: IPEA/INPES. 1978. 260p. (Relatórios de pesquisa 39).

\section{MAHAR, D. J. Government Policies and deforestation in Brazil's} Amazon Region. The International Bank for reconstruction and Development/The World Bank: Washington. 1989. 40p.

PERZ, S. G. Social determinants and land use correlates of agricultural technology adoption in a forest frontier: A case study in the brazilian Amazon. Human Ecology. v.31. n.1. 2003.p.133-165.

WOOD, C. H.; WALKER, R.; TONI, F. Os efeitos da posse do título da terra sobre o uso do solo e investimentos entre pequenos agricultores na Amazônia brasileira. Cadernos de Ciência \& Tecnologia: Brasília. V.18. n.2. p. 95-111. 2001.

\footnotetext{
Abstract - The main objective of this paper was to analyse the factors that influence deforestation in small rural farms of a colonization area in Brazil's Amazon Region. It was used data from 138 small farms distribuited over the transamazonic road in the municipality of Uruará, PA. The data was collected during july and august of 2002. A Tobit model with sample selectivity with etimation in two stages (Heckman) was used. In the first stage, the probability of deforestation was explained mainly by the presence of cattle in the farm. In the second stage, the deforestation area was modeled as a function of various factors. The results showed that the main determinants of deforestation are the amount paid for lired labor, the distance from the main road, the number of cattle heads and the number of people that live in the lot of land.
}

Keywords: Brasilian Amazon, deforestation, colonization, Tobit model 